\title{
Effect of Reperfusion Therapy on Cardiac Rupture After Myocardial Infarction in Japanese
}

\author{
Nahoko Ikeda, MD; Takanori Yasu, MD; Norifumi Kubo, MD; Taishi Hirahara, MD; \\ Yoshitaka Sugawara, MD; Nobuhiko Kobayashi, MD; Shigemasa Hashimoto, MD; \\ Yoshio Tsuruya, MD; Mikihisa Fujii, MD; Muneyasu Saito, MD
}

\begin{abstract}
Background Cardiac rupture after acute myocardial infarction (AMI) is unpredictable and almost always fatal, so the present study reviewed all the clinical characteristics of patients with cardiac rupture to determine if its occurrence can be predicted.

Methods and Results The clinical characteristics of 1,296 consecutive AMI patients from January 1992 to February 2002 were retrospectively evaluated using multi-logistic analysis. Cardiac rupture occurred in 45 patients $(3.5 \%)$, comprising left ventricular free wall rupture $(n=23)$, ventricular septal perforation $(n=20)$ and papillary muscle rupture $(\mathrm{n}=2)$. Early-phase rupture (within $72 \mathrm{~h}$ after AMI onset) was associated with anterior infarction. Of the 45 patients who experienced ruptures, 24 (53.3\%) survived to discharge; $21(46.6 \%)$ of the 45 ruptures occurred after admission. Successful reperfusion therapy was performed within $24 \mathrm{~h}$ for 840 patients. The incidence of rupture was significantly lower for reperfused patients than for non-reperfused patients $(0.6 \%$ vs $3.5 \%$, respectively; $\mathrm{p}<0.01$ ). Peak $\mathrm{C}$-reactive protein concentration was a reliable predictor of late-phase rupture ( $\mathrm{p}=0.01$ ), but not of early-phase rupture.

Conclusions Reperfusion therapy appears to aid in the prevention of cardiac rupture, especially late-phase rupture. (Circ J 2004; 68: 422-426)
\end{abstract}

Key Words: Cardiac rupture; Myocardial infarction; Reperfusion

$\mathbf{I}^{\mathrm{n}}$ $\mathrm{n}$ patients with acute myocardial infarction (AMI), cardiac rupture is the second most common cause of in-hospital death, after pump failure, ${ }^{1,2}$ It is difficult to predict, and almost always fatal. It has been reported that the risk of cardiac rupture is greater for women, hypertensive patients, patients $>60$ years old sustaining their first infarction, 2,3 and patients with a peak C-reactive protein (CRP) concentration $\geq 20 \mathrm{mg} / \mathrm{dl} 4$. However, these associations may change as a result of dramatic improvements in acute phase treatment, including reperfusion therapy by thrombolysis, balloon angioplasty, mechanical circulatory support by intra-aortic balloon pumping (IABP) and percutaneous cardiopulmonary support system (PCPS). Because previous reports have suggested that early- $(\leq 72 \mathrm{~h}$ after onset of AMI) and late-phase rupture ( $>72 \mathrm{~h}$ after onset of AMI) differ in pathogenesis and mechanisms, 56 in the present study we also divided patients with cardiac rupture into the same 2 groups to determine whether we could predict cardiac rupture following AMI from an analysis of the relationships between clinical background and rupture.

\section{Methods \\ Patients \\ Between January 1992 and February 2002, we recruited}

(Received October 9, 2003; revised manuscript received February 16, 2004; accepted February 20, 2004)

Cardiovascular Division, First Department of Integrated Medicine, Omiya Medical Center, Jichi Medical School, Saitama, Japan

Mailing address: Takanori Yasu, MD, Cardiovascular Division, First Department of Integrated Medicine, Omiya Medical Center, Jichi Medical School, 1-847 Amanuma, Saitama, Saitama 330-8503,

Japan. E-mail: tyasu@omiya.jichi.ac.jp
1,296 consecutive AMI patients who had been admitted to the coronary care unit. AMI was diagnosed on the basis of an increase in serum creatine kinase (CK) activity to more than twice the upper limit of normal, accompanied by chest symptoms and electrocardiographic (ECG) changes. Cardiac rupture included free wall rupture (blow-out type, oozing type), ventricular septal perforation (VSP) and

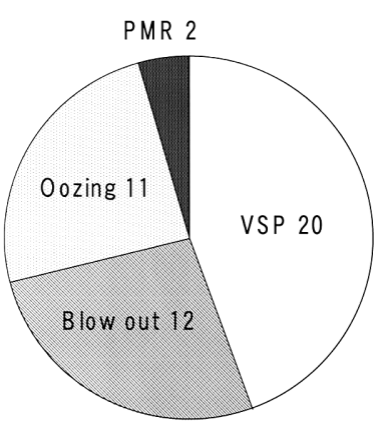

A. Total cardiac rupture 45

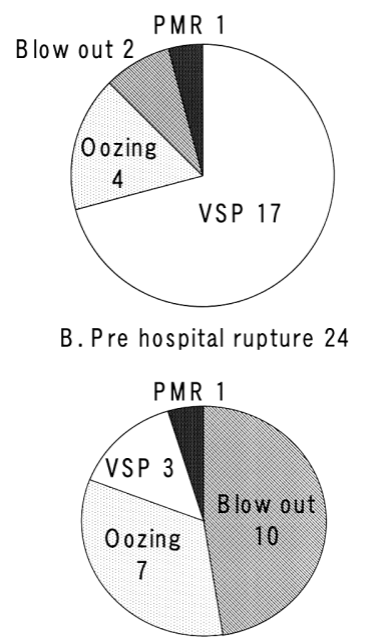

C. In hospital cardiac rupture 21
Fig 1. Types of cardiac rupture. (A) Total cardiac ruptures $(n=45)$. (B) Pre hospital ruptures $(n=24)$ occurred before referral from another hospital for surgery. (C) In-hospital ruptures $(n=21)$ occurred after admission to this hospital. PMR, papillary muscle rupture; VSP, ventricular septal perforation. 


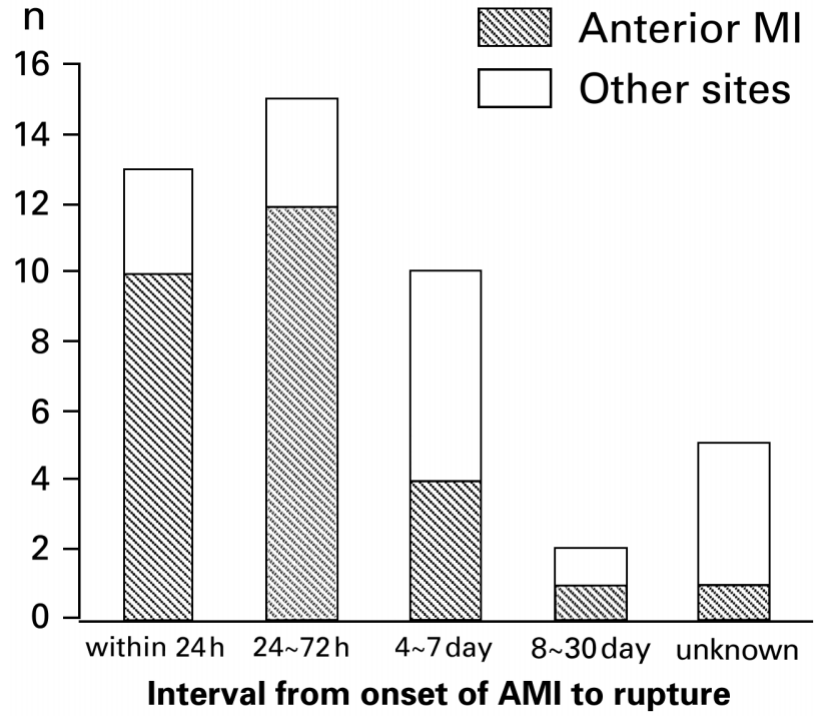

Fig 2. Relationship between time of rupture and site of infarction. Early-phase rupture occurred in 28 patients and was associated with an anterior site. AMI, acute myocardial infarction.

papillary muscle rupture (PMR). Diagnosis of free wall rupture was based on echocardiography followed by pericardiocentesis or surgical or postmortem examination. Blow-out rupture was defined as a free wall rupture with electromechanical dissociation (EMD), and sudden onset of severe hypotension without ECG change, lasting several seconds. Oozing-type free wall rupture required surgical treatment for rapidly increasing pericardial effusion followed by cardiac tamponade. VSP was diagnosed on the basis of abnormal shunt-flow at the interventricular septum on color Doppler echocardiography or a significant increase in oxygen saturation in the right ventricle.

\section{Study Protocol}

The present study design was a retrospective singlecenter case-control study. We reviewed the clinical characteristics of all the patients: age, gender, previous history of myocardial infarction, ST segment elevation on ECG, wall motion abnormalities and pericardial effusion on echocardiography, sites of coronary arterial lesions, grade of collateral flow, peak plasma concentrations of CK and CRP,

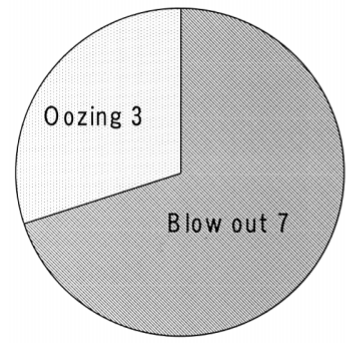

Early phase rupture 10
Late phase rupture 11

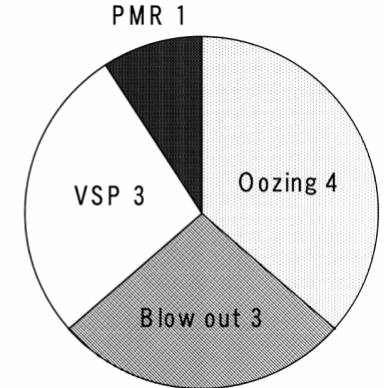

Fig 3. Early- and late-phase rupture. PMR, papillary muscle rupture; VSP, ventricular septal perforation.

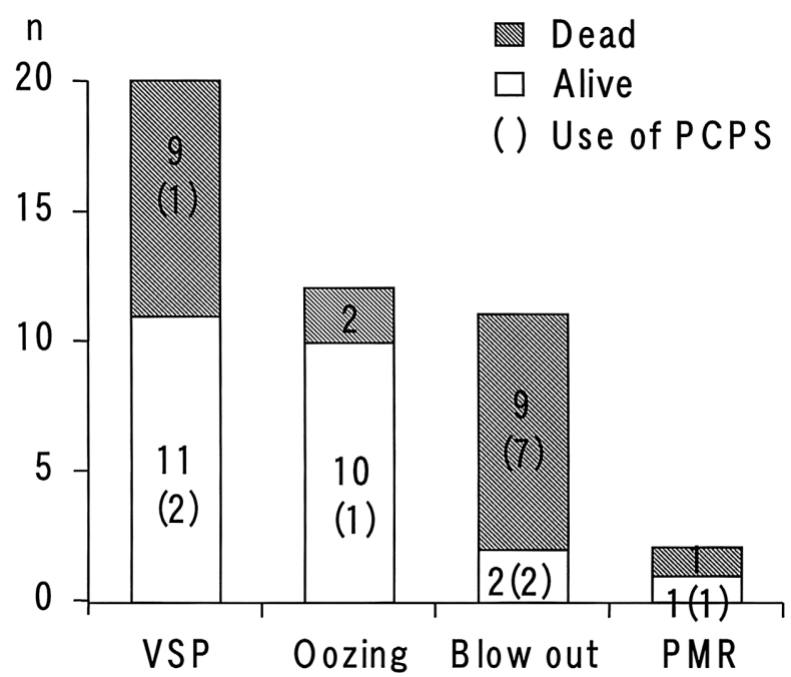

Fig 4. Mortality of patients with cardiac rupture: 24 (53.3\%) of 45 with cardiac rupture survived to the end of the study period. Percutaneous cardiopulmonary support system (PCPS) was used in 14 patients, 6 of whom survived. PMR, papillary muscle rupture; VSP, ventricular septal perforation.

and reperfusion therapy including direct percutaneous transluminal coronary angioplasty (PTCA) and thrombolysis. Reperfusion therapy consisted of administration of thrombolytic agents (urokinase or tissue plasminogen activator (t-PA)) intravenously or into the infarct-related coro-

Table 1 Relationships Between Clinical Factors and Total In-Hospital Cardiac Ruptures

\begin{tabular}{lccc}
\hline \hline & $\begin{array}{c}\text { Total in-hospital rupture } \\
(n=21)\end{array}$ & $\begin{array}{c}\text { Non-rupture } \\
(n=1,251)\end{array}$ & $p$ (vs non-rupture) \\
\hline Acute reperfusion & $5(19 \%)$ & $838(67 \%)$ & $<0.001$ \\
Pericardial effusion & $4(19 \%)$ & $37(3 \%)$ & 0.052 \\
M:F & $14: 7$ & $950: 301$ & 0.067 \\
Anterior MI & $16(76 \%)$ & $600(48 \%)$ & 0.097 \\
Dyskinesis & $11(52 \%)$ & $250(20 \%)$ & 0.124 \\
S ST elevation $(\mathrm{mm})$ & $11.0 \pm 8.2$ & $8.2 \pm 8.9$ & 0.140 \\
Age $($ years) & $68 \pm 10$ & $62 \pm 11$ & 0.191 \\
Thrombolytic therapy & $5(24 \%)$ & $212(17 \%)$ & 0.218 \\
Max CRP $(\mathrm{mg} / \mathrm{dl})$ & $11.9 \pm 8.6$ & $8.1 \pm 5.3$ & 0.101 \\
CRBBB & $3(14 \%)$ & $75(6 \%)$ & 0.433 \\
Max CK $(\mathrm{mg} / \mathrm{dl})$ & $3,314 \pm 2,770$ & $2,660 \pm 2,283$ & 0.542 \\
History of MI & $3(14 \%)$ & $250(20 \%)$ & 0.802 \\
Collateral vessel & $1(5 \%)$ & $225(18 \%)$ & 0.999 \\
\hline
\end{tabular}

CK, creatine kinase; CRBBB, complete right bundle branch block; CRP, C-reactive protein; MI, myocardial infarction. 
Table 2 Relationships Between Clinical Factors and the 2 Phases of Cardiac Rupture, and Comparison of Each Phase

\begin{tabular}{|c|c|c|c|}
\hline & $\begin{array}{l}\text { Early rupture } \\
\quad(n=10)\end{array}$ & $\begin{array}{l}\text { Late rupture } \\
\qquad(n=11)\end{array}$ & $\begin{array}{c}\text { Non-rupture } \\
(n=1,251)\end{array}$ \\
\hline Acute reperfusion & $4(40 \%) *$ & $1(9 \%) *$ & $838(67 \%)$ \\
\hline Pericardial effusion & $2(20 \%)$ & $2(18 \%)$ & $37(3 \%)$ \\
\hline$M: F$ & $7: 3$ & $7: 4 *$ & $950: 301$ \\
\hline Anterior MI & $9(90 \%) *$ & $7(64 \%)$ & $600(48 \%)$ \\
\hline Dyskinesis & $3(30 \%)^{\#}$ & $8(73 \%)$ & $250(20 \%)$ \\
\hline$\Sigma$ ST elevation $(\mathrm{mm})$ & $11.0 \pm 9.6$ & $11.4 \pm 7.2$ & $8.2 \pm 8.9$ \\
\hline Age (years) & $67 \pm 10^{*}$ & $70 \pm 11$ & $62 \pm 11$ \\
\hline Thrombolytic therapy & $2(20 \%)$ & $3(27 \%)$ & $212(17 \%)$ \\
\hline$C R P(m g / d l)$ & $8.3 \pm 8.9$ & $15.2 \pm 7.1 *$ & $8.2 \pm 5.3$ \\
\hline$C R B B B$ & $3(30 \%)^{\#}$ & $0(0 \%)$ & $75(6 \%)$ \\
\hline $\operatorname{Max} C K(m g / d l)$ & $4,391 \pm 3,451$ & $2,112 \pm 1,403$ & $2,660 \pm 2,283$ \\
\hline History of MI & $1(10 \%)$ & $2(18 \%)$ & $250(20 \%)$ \\
\hline Collateral vessels & $0(0 \%)$ & $1(9 \%)$ & $225(18 \%)$ \\
\hline
\end{tabular}

$C K$, creatine kinase; $C R B B B$, complete right bundle branch block; $C R P, C$-reactive protein; $M I$, myocardial infarction. ${ }^{*} p<0.05$ vs non-rupture group; $\# p<0.05$ vs late rupture.

nary artery, PTCA, or a combination of PTCA and thrombolytic therapy. Successful recanalization was defined as thrombolysis in myocardial infarction (TIMI) with grade 2 flow or greater. Patients who had cardiac rupture were divided into 2 groups on the basis of time of rupture: early phase $(\leq 72 \mathrm{~h}$ of AMI onset) and late phase $(>72 \mathrm{~h}$ after onset).

\section{Statistics}

Data are expressed as mean \pm SD. Multiple logistic regression analysis was used to assess the effects of various factors on cardiac rupture in hospital. Chi-square analysis was used to assess differences among categorical variables. A p-value less than 0.05 was considered to indicate statistical significance.

\section{Results}

Details of Cardiac Ruptures

Left ventricular free wall rupture (including blow-out type $(n=12)$ and oozing type $(n=11))$, VSP $(n=20)$ or PMR $(n=2)$ occurred in $45(3.5 \%)$ of the 1,296 patients (Fig 1A). Early-phase rupture occurred in 28 of the 45 patients and was associated with an anterior site of infarction $(\mathrm{p}=0.022)$ Late-phase rupture occurred in 12 patients, and was not associated with any specific infarction site (Fig 2). In 24 patients, rupture occurred before referral to this hospital for surgery; most of these patients had VSP $(n=17)$ (Fig 1B). Approximately half $(n=10)$ of the in-hospital ruptures were the blow-out type (Fig 1C), which occurred more often in the early phase (Fig 3 ).

\section{Percutaneous Cardiopulmonary Support and Survival}

Twenty-four (53.3\%) of the 45 patients survived. PCPS was used to rescue 14 patients from a state of shock (VSP $(n=3)$, free wall oozing rupture $(n=1)$, blow out type $(n=9)$, $\operatorname{PMR}(n=1)), 6$ of whom survived (VSP $(n=2)$, free wall oozing rupture $(n=1)$, blow out type $(n=2)$, PMR $(n=1))$ (Fig 4).

Table 4 Clinical Background of the Patients With In-Hospital Ruptures

\begin{tabular}{|c|c|c|c|c|c|c|c|c|c|}
\hline Age & Gender & Rupture type & Rupture time & MI site & $B P(m m H g)$ & Killip & $R T$ & $C R P$ & $C K$ \\
\hline 52 & $M$ & Blow out & $7 h$ & Anterior & $95 / 60$ & 4 & - & 0.2 & 2,842 \\
\hline 71 & $M$ & Blow out & $7 h$ & Anterior & $105 / 55$ & 2 & + & 0.2 & 2,265 \\
\hline 55 & $F$ & Blow out & $9 h$ & Anterior & $125 / 85$ & 2 & - & 0.1 & 1,420 \\
\hline 69 & $M$ & Blow out & $10 h$ & Anterior & $100 / 60$ & 2 & - & 19.3 & 7,609 \\
\hline 66 & $M$ & Blow out & $12 \mathrm{~h}$ & Non anterior & $160 / 90$ & 1 & - & 0.5 & 3,095 \\
\hline 76 & $F$ & Oozing & $17 \mathrm{~h}$ & Anterior & $130 / 65$ & 1 & + & 2.4 & 2,815 \\
\hline 78 & $M$ & Oozing & $36 h$ & Anterior & $100 / 60$ & 1 & - & 17.1 & 5,573 \\
\hline 76 & $F$ & Blow out & $36 h$ & Anterior & $110 / 75$ & 2 & - & 21.6 & 614 \\
\hline 67 & $M$ & Oozing & $37 h$ & Anterior & $100 / 60$ & 2 & + & 14.2 & 5,550 \\
\hline 55 & $M$ & Blow out & $40 h$ & Anterior & $150 / 100$ & 2 & + & 7.3 & 12,130 \\
\hline 81 & $M$ & PM rupture & $3 d$ & Non anterior & $55 / 40$ & 4 & - & 17.4 & 760 \\
\hline 73 & $F$ & $V S P$ & $3.5 d$ & Anterior & $110 / 60$ & 3 & - & 18.8 & 992 \\
\hline 85 & $M$ & Blow out & $4 d$ & Non anterior & $100 / 70$ & 1 & - & 0.8 & 1,807 \\
\hline 70 & $F$ & Oozing & $4 d$ & Anterior & $100 / 60$ & 1 & - & 15 & 3,195 \\
\hline 51 & $M$ & Oozing & $4 d$ & Anterior & $100 / 60$ & 2 & + & 15.2 & 4,893 \\
\hline 65 & $M$ & VSP & $4 d$ & Anterior & $140 / 80$ & 1 & - & 15.4 & 2,810 \\
\hline 52 & $M$ & Oozing & $5 d$ & Anterior & $110 / 60$ & 2 & - & 6.1 & 1,234 \\
\hline 68 & $F$ & Oozing & $7 d$ & Non anterior & $105 / 60$ & 1 & - & 19.7 & 1,962 \\
\hline 77 & $M$ & Blow out & $7 d$ & Non anterior & $130 / 80$ & 2 & - & 28.5 & 307 \\
\hline 78 & $M$ & Blow out & $8 d$ & Anterior & $100 / 60$ & 4 & - & 13.1 & \\
\hline 65 & $F$ & $V S P$ & $16 d$ & Anterior & $110 / 55$ & 1 & - & 17.3 & 3,160 \\
\hline
\end{tabular}

BP, blood pressure (mmHg); CK, creatine kinase (mg/dl); CPR, cardiopulmonary resuscitation; CRP, C-reactive protein (mg/dl); IABP, intraaortic balloon pumping; MI, myocardial infarction; OMI, old myocardial infarction (-: not exist, +: exist); PCPS, percutaneous cardiopulmonary support; RT, reperfusion therapy (-: not performed or failed reperfusion, +: successful reperfusion therapy); $t$-PA, tissue plasminogen activator (-: not used, +: used). 
Table 3 Management of Cardiac Rupture After Acute Myocardial Infarction

\begin{tabular}{cl}
\hline \hline Blow-out rupture & (Pericardiocentesis) \\
& PCPS, surgical repair \\
Oozing rupture & (Pericardiocentesis) \\
& Oxygenation, colloid infusion, \\
& dobutamine; surgical repair \\
Papillary muscle rupture & IABP $(P C P S)$, surgical repair \\
Ventricular septal perforation & \\
$Q_{P} / Q S \leq 2$ & If hemodynamic state permits, \\
& wait for 2 weeks from onset \\
& of AMI; surgical repair \\
$Q_{P} / Q_{S} \geq 2$ & IABP $(P C P S)$, surgical repair \\
\hline
\end{tabular}

IABP, intra-aortic balloon pumping; PCPS, percutaneous cardiopulmonary support.

\section{Analysis of Clinical Factors}

We analyzed the clinical factors of patients with in-hospital cardiac rupture $(n=21$; Tables 1,2) and found that on multiple logistic regression analysis recanalization of the infarction-related artery most strongly reduced the risk of rupture (especially in the late phase). Occurrence of in-hospital rupture was lower in reperfused patients $(\mathrm{n}=5,0.6 \%)$ than in non-reperfused patients $(\mathrm{n}=16,3.5 \%, \mathrm{p}<0.01)$ (Fig 5). The clinical factor that was secondarily associated with early-phase rupture was anterior myocardial infarction (MI) ( $\mathrm{p}=0.044)$. Peak CRP concentrations were significantly higher in patients with late-phase rupture than in those without rupture $(\mathrm{p}=0.011)$, but there was no significant difference between patients with early-phase rupture and those without rupture (Table 2).

\section{Discussion}

\section{Acute Reperfusion and Cardiac Rupture}

Successful reperfusion of the ischemic myocardium was the factor most strongly associated with prevention of cardiac rupture in both the early and late phases, which is consistent with the findings of previous reports? ${ }^{-9}$ Successful

\begin{tabular}{|c|c|c|c|c|}
\hline Peak time & $O M I$ & $t-P A$ & Management & Result \\
\hline $104 \mathrm{~h}$ & - & - & $P C P S+O p e$ & Alive \\
\hline $15 \mathrm{~h}$ & - & - & $P C P S+O p e$ & Alive \\
\hline $6 \mathrm{~h}$ & - & + & $P C P S$ & Dead \\
\hline $10 \mathrm{~h}$ & - & - & PCPS & Dead \\
\hline $11 \mathrm{~h}$ & - & + & Conventional CPR & Dead \\
\hline $17 \mathrm{~h}$ & - & - & Ope & Alive \\
\hline \multirow[t]{2}{*}{$13 \mathrm{~h}$} & + & - & $I A B P+O p e$ & Dead \\
\hline & - & - & $P C P S+O p e$ & Dead \\
\hline $28 \mathrm{~h}$ & - & - & $P C P S+O p e$ & Alive \\
\hline \multirow[t]{2}{*}{$4 h$} & - & - & Conventional $C P R$ & Dead \\
\hline & - & + & $I A B P+O p e$ & Dead \\
\hline \multirow[t]{2}{*}{$36 h$} & - & - & $I A B P+O p e$ & Dead \\
\hline & + & - & Conventional CPR & Dead \\
\hline $16.5 \mathrm{~h}$ & - & - & Ope & Alive \\
\hline $17 \mathrm{~h}$ & - & + & $I A B P+O p e$ & Alive \\
\hline $19 \mathrm{~h}$ & - & - & $I A B P+O p e$ & Dead \\
\hline $24 h$ & + & + & Ope & Alive \\
\hline $24 \mathrm{~h}$ & - & - & Ope & Alive \\
\hline \multirow[t]{2}{*}{$72 h$} & - & - & $P C P S+O p e$ & Dead \\
\hline & - & - & $P C P S$ & Dead \\
\hline $24 h$ & - & - & Ope & Alive \\
\hline
\end{tabular}

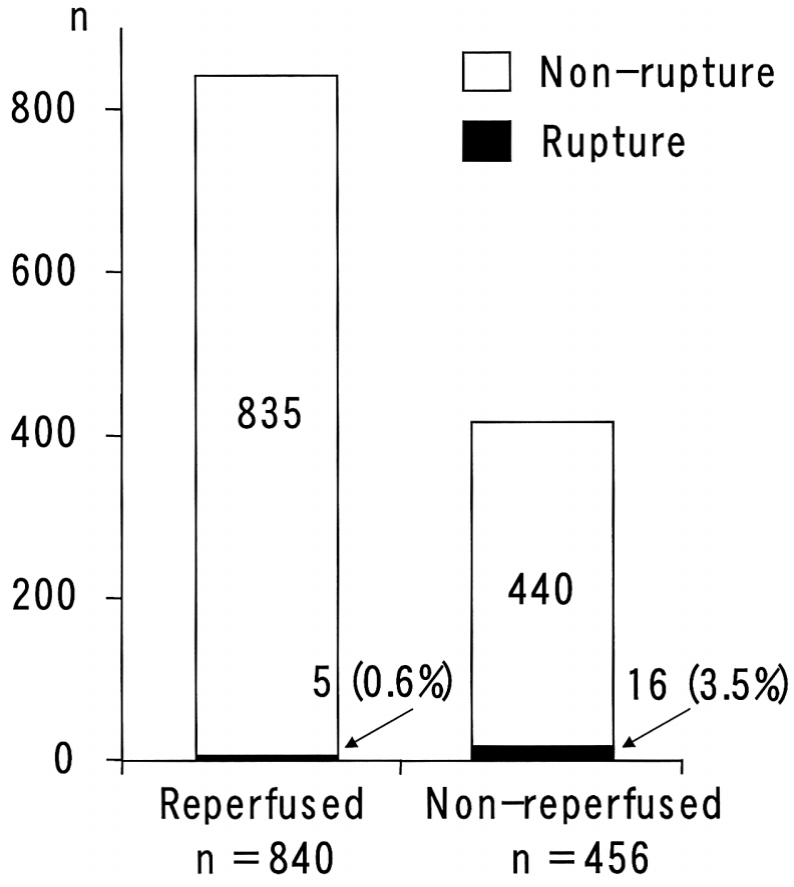

Fig 5. Reperfusion therapy and cardiac rupture. Rupture occurred significantly less in reperfused patients $(0.6 \%)$ than in non-reperfused patients $(3.5 \%, \mathrm{p}<0.001)$.

early reperfusion of the infarct-related coronary artery while maintaining integrity of the downstream microvasculature limits ongoing necrosis, salvages the myocardium, and may prevent the development of shock in many vulnerable patients. Most of the present patients with cardiac rupture who received reperfusion therapy had an earlyphase rupture, which occurred more frequently at an anterior site of infarction, and most (70\%) were the blow-out type. In anterior MI, loss of contraction at the apex may result in a further decrease in apical wall thickness in systole, thus increasing tensile stress per unit cross-sectional area of the apical wall. That suggests an important role for mechanical factors in the development of early-phase rupture. In pathological studies, Becker and van Mantgem have classified cases of cardiac rupture into 3 types: ${ }^{5}$ type I rupture is characterized as an abrupt, slit-like myocardial tear correlating clinically with a recent infarction $(<24 \mathrm{~h})$; type II rupture has an area of myocardial erosion, indicative of a slowly progressive tear; and type III rupture correlates with older infarctions, and the fatal tear typically occurs where an aneurysm has formed. The blow out rupture is thought to be a type I rupture.

We performed direct PTCA in $93 \%$ of reperfused patients, and thrombolysis was performed in $6.4 \%$. In this small number, thrombolytic therapy had no statistical effect on the incidence of cardiac rupture, although many reports indicate that thrombolytic therapy accelerates myocardial rupture. Primary angioplasty restores coronary patency more frequently than thrombolysis! ${ }^{10,11}$ Intramyocardial hemorrhage following reperfusion injury may lead to myocardial tears, especially in patients who receive thrombolytic therapy!2-16

\section{CRP Concentration and Cardiac Rupture}

It has been reported that the peak CRP concentration in plasma is an important predictor of cardiac rupture and left 
ventricular remodelling 4,17,18 Intramyocardial hemorrhage and pericarditis, resulting from slow leakage of blood into the pericardial space early after MI, can participate in local cardiac inflammation, causing marked and persistent elevation of serum CRP. However, in the present study, CRP was only a useful predictor of late-phase rupture, not of earlyphase rupture. In the early-phase rupture group, rupture may have occurred before the CRP concentration peaked.

\section{Management of Cardiac Rupture}

Contemporary methods for management of cardiac rupture after AMI are summarized in Table 36,19.20 In Japan, mechanical support by PCPS in cardiogenic shock was introduced in the $1990 \mathrm{~s}^{21,22}$ and since then, the survival rate of cardiac rupture has risen?23,24 The clinical backgrounds of the present patients with in-hospital rupture are shown in Table 4. Two cases of blow-out free wall rupture were salvaged using PCPS followed by surgery. Their coronary arteries were obstructed at the proximal site of the left anterior descending artery. One of these 2 patients has returned to work, but the other suffered hypoxic brain damage. The time from rupture to start of PCPS is the key to protecting the brain. Conservative strategies that may be used successfully in selected subgroups of patients have been suggested by other researchers $6,25,26$

\section{Study Limitations}

This was a retrospective single-center study, and the number of patients with cardiac rupture was small. Therefore, the present results should be viewed as preliminary, requiring confirmation by larger clinical trials.

\section{Conclusions}

Reperfusion therapy appears to aid in the prevention of cardiac rupture, especially late-phase rupture. Serum peak CRP concentration is an independent predictor of latephase cardiac rupture. However, reperfusion therapy does not adequately prevent ruptures in patients with anterior MI, in whom ruptures are more likely to occur in the early phase. Further research is needed in the areas of pharmacological and mechanical hemodynamic support, refinement of revascularization strategies, and outcome modeling.

\section{Acknowledgments}

We wish to thank Professor Masanobu Kawakami for his critical reading of the manuscript, and Drs Mafumi Ohwa, Taka'aki Katsuki, Nobuhiro Ohmura, Kazuo Matsushima, Yosuke Takagi and Hiroshi Wada for their assistance during cardiac catheterization.

\section{References}

1. Mundth E. Rupture of the heart complicating myocardial infarction. Circulation 1972; 46: 427-429.

2. Bates R, Beutler S, Resnekov L, Anagnostopoulos CE. Cardiac rupture: Challenge in diagnosis and management. Am J Cardiol 1977; 40: $429-437$.

3. Alpert JS. Acute myocardial infarction: Pathologic pathophysiologi$\mathrm{cal}$, and clinical manifestations. In: Braunwald E, editor. Heart disease. Philadelphia: WB Saunders; 1984; $1268-1270$.

4. Anzai T, Yoshikawa T, Shiraki H, Asakura Y, Akaishi M, Mitamura $\mathrm{H}$, et al. C-reactive protein as predictor of infarct expansion and cardiac rupture after a first Q-wave acute myocardial infarction. Circulation 1997; 96: 778-784.

5. Becker AE, van Mantgem JP. Cardiac tamponade: A study of 50 hearts. Eur J Cardiol 1975; 3: 349-358.

6. Figueras J, Cortadellas J, Soler-Soler J. Left ventricular free wall rupture: Clinical presentation and management. Heart 2000; 83: 499-504.

7. Nakatsuchi Y, Minamino T, Fujii K, Negoro S. Clinicopathological characterization of cardiac free wall rupture in patients with acute myocardial infarction: Difference between early and late phase rupture. Int J Cardiol 1994; 47: S33-S38.

8. Nakamura F, Minamino T, Higashino Y, Ito H, Fujii K, Fujita T, et al. Cardiac free wall rupture in acute myocardial infarction: Ameliorative effect of coronary reperfusion. Clin Cardiol 1992; 15: $244-$ 250.

9. Cheriex EC, de Swart H, Dijkman LW, Havenith MG, Maessem JG, Engelen DJ, et al. Myocardial rupture after myocardial infarction is related to the perfusion status of the infarct-related coronary artery. Am Heart J 1995; 129: 644-650.

10. Zijlstra F, de Boer MJ, Hoorntje JCA, Reiffers S, Reiber JHC, Suryapranata H. A comparison of immediate coronary angioplasty with intravenous streptkinase in acute myocardial infarction. $N$ Engl J Med 1993; 328: 680-684.

11. Garcia E, Elizaga J, Perez-Castellano N, Serrano JA, Soriano J, Abeytua M, et al. Primary angioplasty versus systemic thrombolysis in anterior myocardial infarction. J Am Coll Cardiol 1999; 33: 605611.

12. Becker RC, Gore JM, Lambrew C, Weaver WD, Rubison RM. A composite view of cardiac rupture in the United States national registry of myocardial infarction. J Am Coll Cardiol 1996; 27: $1321-1326$.

13. Kawano H, Miyauchi K, Okada R, Daida H, Yokoi H, Miyano H, et al. Histopathological study of cardiac rupture following myocardial infarction with and without thrombolytic therapy. J Cardiol 1994; 24: $249-255$.

14. Shah PK. The role of thrombolytic therapy in patients with acute myocardial infarction presenting later than $6 \mathrm{~h}$ after the onset of symptoms. Am J Cardiol 1991; 68: 72C-77C.

15. Solodky A, Behar S, Herz I, Assali A, Porter A, Hod H, et al. Comparison of incidence of cardiac rupture among patients with acute myocardial infarction treated by thrombolysis versus percutaneous transluminal coronary angioplasty. Am J Cardiol 2001; 87: 11051108.

16. Moreno R, Lopez-Sendon JL, Garcia E, Perez de Isla L, Lopez de Sa E, Ortega A, et al. Primary angioplasty reduces the risk of left ventricular free wall rupture compared with thrombolysis in patients with acute myocardial infarction. J Am Coll Cardiol 2002; 39: 598 603.

17. Ueda S, Ikeda U, Yamamoto K, Takahashi M, Nishinaga M, Nago N, et al. C-reactive protein as a predictor of cardiac rupture after acute myocardial infarction. Am Heart J 1996; 131: 857-860.

18. Ikeda N, Yasu T, Yamada S, Ino T, Saito M. Echocardiographical demonstration of a progressively expanding left ventricular aneurysm preceded by endomyocardial tearing. Circ J 2001; 65: 341-342.

19. Lung B. Management of ischemic mitral regurgitation. Heart 2003; 89: $459-464$.

20. Menon V, Hochman JS. Management of cardiogenic shock complicating acute myocardial infarction. Heart 2002; 88: 531-537.

21. Wada H, Yasu T, Murata S, Ohta M, Kubo N, Fujii M, et al. Rupture of the anterolateral papillary muscle caused by a single diagonal branch obstruction. Circ J 2002; 66: 872-873.

22. Yasu T, Murata S, Katsuki T, Fujii M, Kubo N, Ohmura N, et al. Acute myocarditis successfully treated by percutaneous cardiopulmonary support applied by a newly developed heparin-binding oxygenator and circuits. Circ J 1997; 61: 1037-1042.

23. Reichman RT, Joyo CI, Dembitsky WP, Griffith LD, Adamson RM, Daily PO, et al. Improved patients survival after cardiac arrest using a cardiopulmonary support system. Ann Thorac Surg 1990; 49: $101-$ 105.

24. Matsuwaka R, Sakakibara T, Shintani H, Yagura A, Masai T, Hirayama A, et al. Emergency cardiopulmonary bypass support in patients with severe cardiogenic shock after acute myocardial infarction. Heart Vessels 1996; 11: $27-29$.

25. Masaki N, Arakawa K, Yamagishi T, Tahara T, Miyazaki K, Shibuya $\mathrm{T}$, et al. Oozing-type of left ventricular rupture treated under percutaneous cardiopulmonary support without surgical repair. Circ J 2002; 66: $769-772$.

26. Joho S, Asanoi H, Sakabe M, Nakagawa K, Kameyama T, Hirai T, et al. Long-term usefulness of percutaneous intrapericardial fibrin-glue fixation therapy for oozing type of left ventricular free wall rupture: A case report. Circ J 2002; 66: 705-706. 